\title{
Correction: Palanisamy et al. Shielded Active Gas Forge Welding of an L80 Steel in a Small Scale Shielded Active Gas Forge Welding Machine. J. Manuf. Mater. Process. 2021, 5, 16
}

\author{
Vinothkumar Palanisamy ${ }^{1}{ }^{(D)}$, Jan Ketil Solberg ${ }^{1, *}$ and Per Thomas Moe ${ }^{2}$ \\ 1 Department of Materials Science and Engineering, Norwegian University of Science and Technology, \\ Alfred Getz vei 2, 7034 Trondheim, Norway; vinothvp@gmail.com \\ 2 Department of Science and Industry Systems, University of South Eastern Norway, Hasbergvei 36, Krona, \\ 3616 Kongsberg, Norway; Per.T.Moe@usn.no \\ * Correspondence: jan.ketil.solberg@ntnu.no
}

Citation: Palanisamy, V.; Solberg J.K.; Moe, P.T. Correction: Palanisamy et al. Shielded Active Gas Forge Welding of an L80 Steel in a Small Scale Shielded Active Gas Forge Welding Machine. J. Manuf. Mater. Process. 2021, 5, 16. J. Manuf. Mater. Process. 2021, 5, 79. https://doi.org/ 10.3390/jmmp5030079

Received: 3 June 2021

Accepted: 4 June 2021

Published: 27 July 2021

Publisher's Note: MDPI stays neutral with regard to jurisdictional claims in published maps and institutional affiliations.

Copyright: (c) 2021 by the authors. Licensee MDPI, Basel, Switzerland. This article is an open access article distributed under the terms and conditions of the Creative Commons Attribution (CC BY) license (https:// creativecommons.org/licenses/by/ $4.0 /)$.
The authors wish to make the following corrections to this paper [1]:

Change in Section 2 Materials and Methods

Section 2.1 As-Received Steel

In line 6 of the original paper, a wrong hardness number for the as-received steel was given. The hardness number "728 HV" should be changed to "227 HV".

\section{Changes in Section 3 Results}

During the writing of the original paper, the hardness graph of weld W3 (forged at $950{ }^{\circ} \mathrm{C}$ ) in Figure 10 was mixed up with the hardness graph of weld W2 (forged at $1150{ }^{\circ} \mathrm{C}$ ). Due to this, it was wrongly assumed that weld W3 did not follow the trend of the other welds (that were forged at higher temperatures) with respect to the width of the heat affected zone. The following changes should be done to Sections 3.1 General and 3.3 Hardness:

Section 3.1 General

In paragraph 2, line 9-14, the sentences "It is believed that a reasonable estimate of the width of the heat affected zones can be obtained from the temperature graphs in Figure 4. This seems especially to be the case for the two highest forging temperatures, which is seen by comparing Figure 4 with the hardness plots in Section 3.3. The reason for the good correspondence between the $1150{ }^{\circ} \mathrm{C}$ and $1300{ }^{\circ} \mathrm{C}$ temperature profiles of Figure 4 and the hardness plots for the same temperatures is that the temperature plots at any distance from the weld line probably represent the maximum temperature that was obtained during the welding process." should be changed to "It is believed that a reasonable estimate of the width of the heat affected zones can be obtained from the temperature graphs in Figure 4, which is seen by comparing Figure 4 with the hardness plots in Section 3.3. The reason for the good correspondence between the temperature profiles of Figure 4 and the hardness plots for the same temperatures is that the temperature plots at any distance from the weld line probably represent the maximum temperature that was obtained during the welding process."

In paragraph 2, line 24-27, the sentence "Therefore, the temperature graphs for the two highest weld temperatures are assumed to define the heat affected zones of the welded specimens quite well, and to some degree also define the microstructures that can be expected there, although these microstructures also will strongly depend on the local cooling rate." should be changed to "Therefore, the temperature graphs are assumed to define the heat affected zones of the welded specimens quite well, and to some degree also define the microstructures that can be expected there, although these microstructures also will strongly depend on the local cooling rate." 
In paragraph 2 , line 31-40, the following sentences should be deleted: "From the hardness plot of weld W3 in Section 3.3, it is seen that the heat affected zone that was produced at the lowest welding temperature of $950{ }^{\circ} \mathrm{C}$, is wider than the heat affected zones of the specimens that were welded at the two higher temperatures (low hardness values continue to $7.5 \mu \mathrm{m}$ from the weld line). The reason for this is not obvious, but might be associated with the low forging temperature at which the flow stress is much higher than at the two higher welding temperatures, so "significant" deformation heat may have developed and caused the specimen temperature to increase above the temperature profile in Figure 4 for all distances included in the plot. The temperature graph for $950{ }^{\circ} \mathrm{C}$ will therefore to a lesser degree define the HAZ width than what the graphs for $1150{ }^{\circ} \mathrm{C}$ and $1300{ }^{\circ} \mathrm{C}$ do."

\section{Section 3.3 Hardness}

In paragraph 1, line 8-11, the following sentences should be deleted: "The hardness profile of the pipe that was forge welded at $950{ }^{\circ} \mathrm{C}$ (weld W3), deviates somewhat from this pattern since it seems to have a wider $\mathrm{HAZ}$ than the pipe that was forge welded at $1150^{\circ} \mathrm{C}$ and cooled at the same low rate of $1^{\circ} \mathrm{C} / \mathrm{s}$ (weld W2). The reason for this has been discussed in Section 3.1."

In the figure captions of Figures 9 and 10, the unit of the given distances from the weld line should be changed from " $\mu \mathrm{m}$ " to " $\mathrm{mm}$ ".

These changes have no impact on the conclusions of our paper (they are only positive). The authors apologize for any inconvenience caused and state that the scientific conclusions are unaffected.

Conflicts of Interest: The authors declare no conflict of interest. The industrial sponsors had no role in the design, execution, interpretation, or writing of the study.

\section{Reference}

1. Palanisamy, V.; Solberg, J.K.; Moe, P.T. Shielded Active Gas Forge Welding of an L80 Steel in a Small Scale Shielded Active Gas Forge Welding Machine. J. Manuf. Mater. Process. 2021, 5, 16. [CrossRef] 